\title{
Giumus;ehrer.
}

Bon Brof. Dr. (S) raf zu Leintngen, Bien.

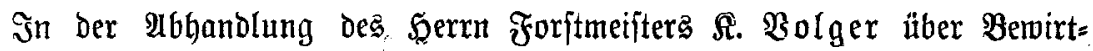

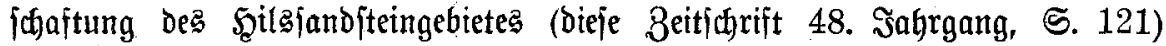
findet jïh eine Inmerfung folgenden Inhaltes: "Reiningen läbt in $\mathfrak{R}$ ubners

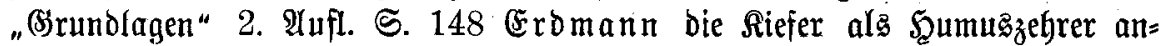
geben." Bur Bermeidung etwaiger unzutreffender $\mathfrak{A}$ nfichten über meinert eigenent

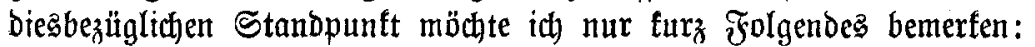

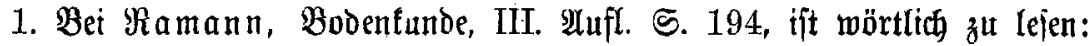

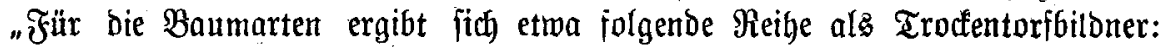

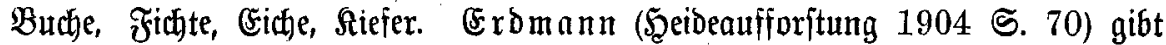
Die Reihenjolge: $\mathfrak{B s e n m o u t h s f t e j e r , ~ B u c h e , ~ F i t h t e , ~ T a n n e , ~ E i c h e , ~ S i t e f e r , ~ B i r f e . ~}$

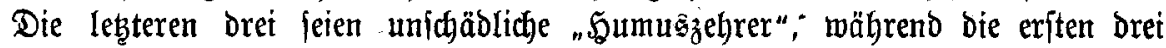
ausgeiprochene "Scumuß̧bildoner" find ufw." Demnach dürfte mein Bitat als jolches toobl einmandfret fein.

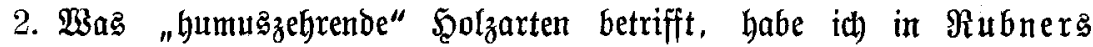
(Srundlagen के. 148 ausführlich (auf $1 \frac{1}{2}$ Seiten!) Dargelegt, wie jebr bie Injichten ber einzelnen Autoren ausetander geben; idh habe

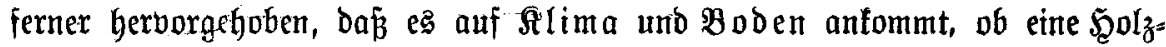
art in einer beitimmten (segend Sumusmehrer oder zzebrer ift; ich habe

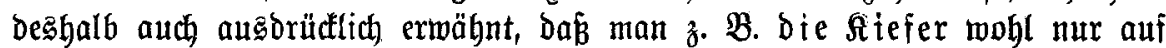
humuszebrenden Sanden als Fumugzehrer bezethnen fann, folches auf (Srund ber Siteratur, brieflicher Mitteilungen von F̧errn $\mathfrak{B r o f . ~ D r . ~ \Re . ~ \Re l b e r t ~}$

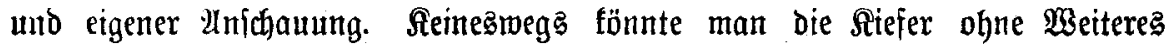
ctwa als Şumuszebrer bezeicfnen.

\section{2 ü̈cheranjeigen.}

Mr. 49.

\section{Patgeber für bie Eozinlverfitherung.}

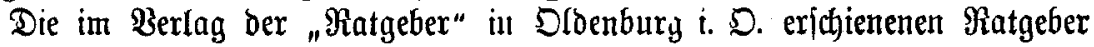
für bie Sozialverfitherung haben bereits weite Berbreitung gefunden. Bis jegt jind erichienen und auf ben neueften Stand ber Bejebgebung gebracht:

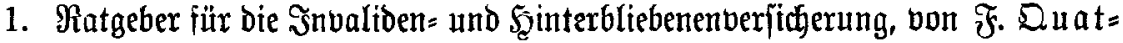

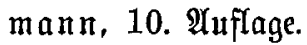

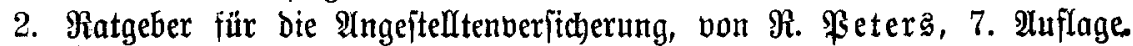

3. Ratgeber Für Die Rrantenverfitcermng, von $\mathfrak{A}$. Than, 3. Anflage.

4. Ratgeber für bie Unjallverjicherung, von $\mathfrak{F}$. Rleeił, 2. Auflage.

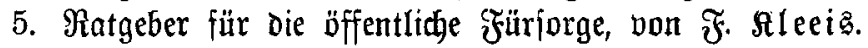

